\title{
Reflections on Communication Processes and Virtual Teams by Lecturer and Student Cohort: a Case Study
}

\author{
Kathy Egea \\ Central Queensland University, \\ Rockhampton, QId, Australia \\ k.eqea@equ.edu.au
}

\author{
Shirley Gregor \\ Australian National University, \\ Canberra, Australia \\ Shirley.Gregor@anu.edu.au
}

\begin{abstract}
This paper explores processes and outcomes from virtual teamwork in a university course in HumanComputer Interaction. The course has students both on- and off-campus, with a very wide geographic distribution. The novel approach adopted in the course organized students into both small teams (three students) and into larger units (a group of six teams). Teams worked collaboratively, using a variety of communication channels: email, chat groups, face-to-face, and phone. Each team was responsible for preparing a power-point presentation that incorporated human-computer interaction design principles, that was then critiqued by other teams in their 'group'. Overall, students' experiences were extremely positive and recognized learning that contributed to course goals and effective virtual teamwork. Reflections on the processes involved in successful teamwork indicated that important factors included clear goals for the team, good task organization, similar personal achievement goals among team member, reliability and efficiency, open communication styles, and respect and understanding for others in the team.
\end{abstract}

Keywords: virtual teams, communication, assessment, distance learning, human-computer interaction.

\section{Introduction}

The increasing availability and use of the Internet has made the topic of virtual teams one of significant interest to many organizations. Virtual teams are teams that communicate using a variety of communication media across a continuum of space and time configurations. Such teams allow organizational members separated by geography and time zones to work collaboratively using the Internet and other media for communication.

In this paper we explore the processes and outcomes from virtual teamwork for assessment tasks in a university subject in Human-Computer Interaction (HCI). The tasks required each student team to present a virtual seminar, perform several peer reviews of other team presentations, summarize the reviews of their own presentation, and to reflect on improvements suggested in the reviewing process. These tasks were designed to increase students' understanding of communication processes supported by technology, an essential element of Human Computer Interaction, as well as providing an opportunity to learn about virtual teamwork.

The paper includes the reflections of the lecturer who designed the course as well as the reflections of the

Material published as part of these proceedings, either on-line or in print, is copyrighted by Informing Science. Permission to make digital or paper copy of part or all of these works for personal or classroom use is granted without fee provided that the copies are not made or distributed for profit or commercial advantage AND that copies 1) bear this notice in full and 2) give the full citation on the first page. It is permissible to abstract these works so long as credit is given. To copy in all other cases or to republish or to post on a server or to redistribute to lists requires specific permission from the publisher at Publisher@infomingsetence.org students who worked in the small virtual teams. The concepts that are developed in this paper include both the use of virtual teams and the communication interactions that create a community of learners involved in a virtual team (Turkey, 1995; Robey, Koo and Powers, 2000; Haythornthwaite, Zkazmer Robins, and Shoemaker, 2000). 


\section{Conceptual Background}

This section relates the motivations and the pedagogy of virtual teams in the assessment strategy underpinning the assessment process. It also briefly summarises the literature for generic virtual teams.

\section{Motivations for $\mathrm{HCl}$ assessment tasks}

User-centred design, the integration of knowledge from a variety of disciplines and iterative development reflects the design framework of Human Computer Interaction (HCI). Evaluation is the central hub of this process. Assessment strategies need to incorporate these concepts for the student to understand the importance of this discipline to the software industry. This assessment requires peer review and reflection. This is a process required of the virtual team.

Further, and more recently, researchers and educators in the discipline of Human-Computer Interaction have realised the important of the social aspect of communication to enable reflection on design improvements in software design. Preece et al. (1994, 173-174) state:

...the social aspects of Human Computer Interaction have been much neglected, a situation that needs to be readdressed. ... This involves analysing how people communicate with each other and how they interact with the variety of artefacts that constitute their work environment.

The focus on social interactions particularly with computer technology and the construction of knowledge within this environment affords the use of virtual teams, mail groups and seminar presentations. The use of the virtual team enables the students to determine their own methodology to solve the task of team presentation and peer review of other team seminars. It was expected that students would actively dialogue in collaboration on HCI concepts and their application.

A second motivation for the use of virtual teams is the link with the global work environment. De Lisser (1999) cited in Smith (2000) indicates that the ability of students to work in virtual teams satisfies an increasing demand in recruitment and retention strategies of employees. Deems (1998) links intrinsic learning that occurs in the work environment to a self-knowledge developed in a climate of connectiveness and a continual context for learning and self-knowledge. Hence, by incorporating authentic activities that are relevant to the global employment model for the information technology or information systems student, students are able to reflect and modify their understanding, as well as develop intrinsic skills required in the workplace.

\section{Pedagogy - Using Virtual Teams to Improve Learning Outcomes}

The rationale of the virtual team approach was to stimulate an online environment that encourages student interaction and develops communication skills, through the team creation of a virtual seminar presentation. The team members share in the development of the assignment presentation, reducing the load for any one student. The team framework supports the development of interpersonal skills, sharing information, commitment to team goals, cooperation and satisfaction. Challenges to be meet in the virtual environment are trust, communication, tight deadlines and team comphensiveness (Smith 2000). The achievement of these skills supports the communication concept through the team interaction.

Roberts, Romm and Jones (2000) outline two similar models of virtual teams using group and subgroup work. The model defined in the current paper combines the radical model, wherein students work individually to present a seminar paper and then assess the presentations of several other members of a larger sub-group, and the naïve model, which uses small teams without interaction with a larger group, into a model that includes the dynamics of small team interactions, interwoven into group tasks. The small team tasks include the seminar presentation and reflection on critiques for improvement of team seminars, while the group focus is the peer review of other presentations. This model takes into account the dynam- 
ics that a sub-group or team can achieve in terms of communication online, improving their interpersonal skills and goal achievement. As a consequence it supports the principles of user-centred design where improvements to a presentation are made based on user critique, reinforcing the subject matter in the subject discipline (see Preece et al. 1994, p. 46).

Gay et al. (1999) and, later, Lipnack \& Stamps (2000) indicate that there is conflicting evidence on the role of how particular technology supports the group and team dynamics in terms of coordination and communication. Smith (2000, p. 5) sums this by commenting "virtual teams are challenged because they are virtual." To address this disadvantage, virtual teams will be able to choose their own means of communication, which includes face-to-face communication. Since the students are studying in distance mode, they will be geographically grouped.

\section{Literature on Virtual Teams}

The importance of the use of the virtual team concept in organizations is recognised by the ACM [Association for Computing Machinery] (Faucheux 1997; Hardwick \& Bolton1997). Virtual teams used by the global economy communicate synchronously and asynchronously with email, and synchronously with telephone and video conferencing (Fisher, Bibo \& Youngsmart 2000). Thus the use of student team projects and the underlying communication skills is highly recommended as an undergraduate skill, particularly in the Information Technology and Information Systems discipline areas.

Based on a review of literature, Aspin (1999) provides a summary of virtual teams in education. Key points relevant to this study are presented for comparison with the reflection data presented in this paper.

Factors that lead to successful teams include

- $\quad$ need to follow strict guidelines

- most important element is communication between team members

- concurrence on frequency, degree of formality, structure and openness of information exchange is crucial to meet deadlines and maintain healthy group

- members must communicate directly with each other rather than through a team leader - this requires software designed for groups (groupware)

- immediate feedback

- must have common goals

- all members need to contribute

- socialising is important in development of common goals, commitment to team task, group pride need outlets to build group spirit and prevent conflict

- members must be handpicked

- need a set of behaviours such as daily logging in, communicating formally and informally, coping with information overload, projecting virtual presence to others over the Internet

Virtual teams barriers include:

- psychological distance

- lack of common goals

- $\quad$ social and cultural barriers

- inability of members to adapt to new ways of doing things 
Appropriate rules of behaviour need to be established (Haythornthwaite et al. 2000). This generates a comfort level within the virtual environment, and allows participants to invest time and trust in their communications with other team members. "As they build stronger, more intimate ties, they gain access to the kind of support and continuity that underpins community, moving the individual from a position of isolation to membership in a known community." ( Haythornthwaite et al. 2000, p.5).

While computer mediated communication is typical of virtual teams, other communication processes can be used to sustain levels of interpersonal ties. Haythornthwaite et al. (2000, p.16) indicate that public and private communication is important for students:"Email, IRC whispering, and the telephone fill an important niche for students providing private, person-to-person contact."

Jarvenpaa, Knoll and Leidner (1998) argue that temporary groups move away from interpersonal relationships, instead they refer to the activity of swift trust. Characteristics include highly social initial meeting, with ongoing communication based in task and social information, proactive orientation, task orientation, positive tone, task goal clarity, role division and specificity, time management, substantial feedback on work and frequent communication with prompt responses (Jarvenpaa et al. 1998). Teams tend to have positive expectations of other team members reliability based on very little real information. Jarvenda \& Leider (1998) indicate that the first interactions initiate the tone of the working relationship. Interestingly, the virtual teams interact both with swift trust yet develop a keen interpersonal understanding of their team members.

The reflections from the lecturer and student in the case study are shown to be consistent in part with the literature presented above. In particular, comparisons are made in term of communication styles, team interactions, success factors and barriers.

\section{Research Methodology}

Data for the study was gathered from the material submitted by students, which contained their reflections on the course, from course materials and from archived mailing lists. The open-ended questions that guided the student reflections are shown in section 5.2

\section{Case Study Description}

\section{Context}

This study explores the communication strategies used in virtual teams for the completion of an assessment instrument (25\% of course weighting). The course used for this case study, was COIS12036 Human Computer Interaction, taught at a small regional university in the state of Queensland, Australia. The course is taught to students with at least one year's tertiary study experience, and undertaking undergraduate programs in Information Systems $\left(3^{\text {rd }}\right.$ and $4^{\text {th }}$ year students), Information Technology $\left(2^{\text {nd }}\right.$ and $3^{\text {rd }}$ year students) or Multimedia students ( $2^{\text {nd }}$ and $3^{\text {rd }}$ year students).

Students are enrolled as external students located locally, regionally, within Queensland, in other states of Australia or at various international locations, for example, England or Jamaica. Students receive a CDROM disk with the course profile as well as a detailed paper study guide and resource book. The course profile has the assignment requirements, weightings and due dates. A website is available with current lecture slides, tutorial and laboratory activities. As well, other resources support student learning and include assessment examples. The case study for this paper is concerned with the first assignment, involving team-seminars, team-review and team-reflections on improvements for the seminar; 


\section{Learning Objectives and Assessment}

While the overall aim of the course is to advance student understanding of design principles of meaningful interaction between the user and the computer inherent to Human Computer Interaction, the aim of the assignment in this case study is to develop meta-skills in communication.

The intention of seminar presentation was the simulation of a live presentation, through the use of PowerPoint notes facility. Student teams were expected to create some form of cognitive dialogue between the target group and the medium, which reflects an understanding of the content and principles of HCI.

For external students, this is the submission of a seminar presentation to a virtual audience; for the regional internal students the seminar is presented to a live audience via a videoconference link to four campuses; and for the international students the seminar is presented to a live audience in the same room. For this case study, the virtual aspects of the external students will be covered. The assignment required that students be placed in virtual teams of three members. Collections of six teams were placed into individual and discrete groups, each with their own mailing list.

The website for this course had a set of lectures on teamwork. Central to these slides were the delineation of team goals, the understanding of the team task, the rules required for effective and supportive team interaction, the nurturing of trust and respect for all team members, the ideas of team leadership, decision making, ideas for team to solve interpersonal problems and honouring one's own ideas. However, email discussion techniques and email etiquette was not given. Since class mail lists were part of the culture for online learning, such detail was not considered essential.

Each week, a single virtual team present a simulated 'live' 15-minute seminar presentation of a HCI topic to a group mailing list in the form of an attached file. The other five teams within the group reviewed the presentations and provided feedback to the presenting team using a formatted review sheet supplied online at the website for the course. These reviews were also sent to the individual group mailing list as attached files within the same week as the presentation.

At the end of the assignment period, each team had submitted a presentation and five reviews for each of the five other seminar presentations for their group. Teams were then asked to present a summary of the reviews from the other teams. Reflection on this summary was documented to indicate improvement for the presentations. Individual students, and not teams, were then required to document the processes of communication within the teams and the methods the team used to complete the assignment. Finally students were asked to reflect on the experience of the virtual team dynamic, particularly in terms of affective notions. It is from this final documentation that the following reflections are categorised.

\section{Structure of Virtual Teams into Groups}

A central theme that underpinned the assignment was the simulation of the global working environment. Groups were a collective of scattered working teams, with each team positioned in separate regions or cities. From the student perspective, each student belonged to a team of three students that was part of a mail list called a group. Each group had 6 teams.

While several iterations of this assignment have occurred over the last 4 years, the current design for virtual teams was structured around regions of living. Teams were generated from a student database through the association of postcode. At the start of the semester, students were placed in the mailing list and informed of their team members (name and email address).

\section{Reflections on the Case Study}

This section describes the lecturer's reflections on the creation of the virtual teams and the outcomes from this learning environment, while the student reflections focus on the virtual learning environment in terms of participation and outcomes. 


\section{Lecturer Reflections}

The lecturer has provided these reflections based on personal description of the activities in the course during the winter semester (July to October) in 2001. The reflections provided here include the learning environment developed using virtual teams and the learning outcomes based on student response to assessment criteria.

\section{Creating the learning environment: virtual teams and groups}

This section described the organisational structure of the virtual teams, the student activity within the virtual teams and reflections on the suitability of the team and group structure.

\section{Setting up the group mail lists}

In all, there were five external mail groups and two internal mail groups. Each group had 18 students attached to them. In one case, a student requested that he would prefer to be a team of one. As the student understood the requirements of the assignment, he offered to comment on teamwork from his earlier experiences of teams. The decision was granted to this student with the view that such a trial would be worthwhile. It may be considered that future offering of this course could offer this choice, provided the student was willing to do the work required in the assignment.

\section{In-term activities with virtual teams}

Once the groups were active using the mail list, and the addresses were correct, very little interaction was required by the lecturer (list owner). Teams were busily attaching their seminar slides and peer reviews to the group mail list.

The mail lists were also archived on the course web page for historical reasons as well as backup in case of technological failure. As the semester concluded, and the summaries were being completed, this archived mail list was invaluable.

Problems arose with student postings to the mail list when they used different mail addresses to send their messages. Since the list was closed for each mail group, the simplest means to deal with this was to add the new address to the list.

\section{Discussion on team size}

With attrition, several students withdrew from the course. This caused some teams to be reduced in number. As a consequence, the assignment load for the smaller teams was reduced in part. As indicated in the student discussion, teams of larger size (greater than three) were considered to be unsatisfactory. Students indicated that larger membership increased the possibility of some members not participating, but relying on others to do the work.

\section{Groups and teams}

The division of groups into small virtual teams, was significant to the success of this assignment. The model of six teams of three students to form a group is not unlike the small tutorial, or even a community of learners with the common goal of presentation and review. The assignment structure created the environment where participation was the norm and at the same time quite timely. Students indicated that the view of other assignments and the immediate feedback that they got for their own presentations created a learning environment that was most useful in the understanding of the concepts underpinning the course content.

After an initial flood of email regarding the seminar and review structure, no student indicated disapproval for the assignment. A few students were not happy with the team members that they were given. Two teams (of 42 teams) did not participate. However, the majority were satisfied with their community of learners. 


\section{Attainment of learning objectives: process of communication}

The HCI goals underpinning the assignment were to engage students in an understanding of the process of communication through email conferencing, using the interface to simulate live presentations and using word files to provide constructive feedback.

Some teams developed guidelines for team interaction to ensure a smooth process of communication. The team interactions demonstrated that the goals of the assignment were achieved. There was an understanding of the rationale for clear communication since students indicated that they adapted their communication strategies on email, in the search for efficiency and effective communication.

Most seminar presentations were extremely well done. While students commented when notes were not clear, most were generally very positive in their reviews on target suitability. Communication from the screen design in the seminar presentations was judged by the clarity of the interface, and the notes provided. The knowledge presented in the seminars included current information of the course modules, which extends the content beyond the notes provided in the study guide and the set text. As such, it is a most useful exercise for pedagogical reasons.

The peer review presented by the teams indicated that students were guided by the design guidelines for screen presentation and navigation. This reinforces student comphrension of population differences, and user testing, which underpin the evaluation philosophy of the HCI discipline.

\section{Student Reflections}

As part of the assignment, students were asked to reflect individually on their communications between team members and to comment on the use of teams. The questions that were asked included:

Document (support by email interchange)

How you introduce yourselves

How you arranged to engage in communication

How you organised the seminar presentation

How you organised the seminar reviews

Discuss

How you feel your team worked together

What were the positives that you gained from working as a team

What would you try to avoid next time when you are in a team

Any other points you wish to raise

The following sections summarise the central features that were of interest to this reflection of the use of virtual teams in an advanced distance course.

\section{Learning environment: virtual teams}

This section provides the student reflections towards their learning environment. The students used the virtual teams to effect a collaborative and consultative learning environment. Benefits and frustrations were expressed in the student reflections, which have been summarised and presented below in 5.2.1.2. Students also described the factors that promote a successful team environment (section 5.2.1.3). Finally issues that arose from student reflections of virtual teams are presented in section 5.2.1.4.

However, it is appropriate to put the reflections of one student as vignette of the virtual team experience. While important concepts have been bolded to allow the reader to scan the passage, it was decided to keep much of this large passage to provide the context of the content. 
Reflections on Communication Processes and Virtual Teams

.. three members are located in three different countries... The group managed to achieve their goals and have developed a good professional relationship...The goals of the group were to communicate with each other on a regular basis to produce a PowerPoint presentation on ...

The group began the first major task by developing a strategy and allocating individual tasks in order to accomplish the production of the PowerPoint presentation. ... Each group member did their own research to report on the menu driven system they had chosen. .. The group members would write an updated version of the presentation and send it to the others, after making the changes and suggestions, to achieve a group consensus for the final draft of the presentation. In general, each group member worked efficiently and did much to help the others to achieve a greater understanding of the topic and the assignment criteria. During this initial period of interaction, there was a very positive feeling in the group, which produced a good working environment for the presentation through emails that offered encouragement, compliments and positive feedback by each member of the group. Therefore, the first stage of assignment 1, the PowerPoint presentation, was finished and submitted on time through a good working relationship in the group.

However, in the week following the group's positive contact broke down due to Charis not understanding the assignment requirements, and submitting a review without the whole group's final consensus. Les reacted quite badly to this, and it resulted in a significant amount of friction between the two members for about one week. After the issue of the importance of obtaining a group consensus for the review through greater communication by all group members had been resolved, the groups email interaction returned to it's normal state, with regular email contact between the group to do the weekly reviews. ..

At the conclusion of the semester, the group members had very high morale towards each other, despite the earlier disagreements. Overall, the group communicated very well via email on a regular basis to achieve the goal necessary to pass the subject, and is a great example of how email can link people from all over the world together for the purpose of working and communicating together to achieve goals.

\section{Student-determined learning environment}

Students who were aiming for high assessment marks, tended to nurture their working environment by providing supportive and encouraging comments to the other members of the team. They developed a high level of team efficacy and team morale. Personal contact was regarded as essential early in the team interaction. This was done via a phone call or a face-to-face meeting, if possible. Being personally friendly with team members created a friendly environment, enabling students to feel comfortable to explain their own thoughts without fear of criticism. It was noted that teams with team members that had prior team experience, including work-mode teams, were more productive and efficient working environments. 
At the other end of the virtual team spectrum, some students did not contact their teams early in the semester. These students indicated that they had not read the course profile and were quite vague regarding the purpose of the assignment. This caused a lot of stress to other team members. In one case, the team members excluded the third member from the presentation, as his effort was too late to be of use to the prepared seminar.

However, overall, $90 \%$ of student teams judged themselves as successful and had participated in all aspects of the assignment, including the seminar and the peer reviews. Interestingly, teams were either totally collaborative with the peer review for each week, or were singular, allocating a review to a different team member for each week of presentation. However, in both cases teams indicated general satisfaction with their efforts and the peer reviews that they received.

As indicated in the earlier section, one student asked to be allowed to work individually and not in a team. In the assignment reflection on teams, this student tabled a comparison of positive factors and negative factors of individual work when compared with teamwork. He compared this with his observations of the other teams in his mail group. Positives included: flexibility, no team overheads (team management, team consensus both of which are very time consuming), and no negative dynamics (no stress due to personality differences, no unequal contributions). The negative factors included: work overload, and no team synergy, loss of team expertise and fresh ideas, no feedback from team members, possibility of noncompliance with assignment due to lack of collaboration.

\section{Benefits of virtual teams}

One student, (group 15, team 5) observed that "some teams were synergic by nature and the result of their work exceeded the sum of their individual skills and contributions". The sharing of the assignment across several team members lightened the distance student load and as such was highly acceptable.

Students commented that the activities reflected real situations where teams needed to plan for deadlines, and to get a better understanding of the level of commitment and organisation needed for working as a team in industry. Some students noted that they released their desire to control the assignment outcome by trusting others to achieve their promised tasks. Other students found this difficult and took control as team manager.

Students agreed that the assignment style and team communication was a suitable activity to achieve the desired communication goal underpinning the Human computer interaction framework. Further, enthusiastic support was given to the usage of teams for the assignment. Comments included

"It was rewarding to be in an enthusiastic team"(group 13 team 3);

"It was rewarding to be in a team that presented a good seminar and to have other teams review is positively."'(group 14, team 4).

\section{Frustrations}

Several teams made comments that email usage did not match individual students work environments.

Some students work full time while others part time. Some students used work emails, while others used a mail service provider from their home. As a consequence, the use of timely email was challenging for these students. Students wanted as close to synchronous contact as possible. To overcome this, if the team members were locally based, they would contact team members by phone and more than likely set up at least one face-to-face meeting. Teams that worked successfully when internationally based, drew up agreed guidelines for communication. For example, a member of an internationally based team stated in his reflections:"I specified to the team that any mail sent to me would be responded to within a 24-hour time frame and adhered to this commitment." (group 11, team 2).

There were two teams of thirty external teams that did not work comfortably. The team members indicated that there was poor response to email, poor communication skills or team members were not reli- 
Reflections on Communication Processes and Virtual Teams

able. One student noted that "the tone of the emails became impolite, students got worked up and were really blunt" and indicated that "participants needed a course on netiquette."

\section{Key factors for a successful virtual team}

Success was noted to be based on team tasks and students' concept of teamwork. It was indicated that the tasks were clearly defined in the course profile, stating what was required in the seminar presentation; the peer review and the summary and reflections. Teams were judged to be successful when they had clear goals for interaction; were timely in their organisation of tasks; organised tasks into subtasks with team members, and had one team member who collated comments for team agreement. It was also noted that leaders were not necessary when teams were both small and equally motivated.

In summary, the student data described the person type for successful teams: The student needs to be

- Similarly motivated to other team members

- Similar level of achievement goals

- Self-motivated participants

- Enthusiastic members

- Consciousness of other team members

- Responsible

- Reliable

- Consistent

- Professional

- Friendly

- Encouraging

- Open communicator

- Able to communicate freely, and effectively

- Able to work collaboratively

- Respect team rules for activities

- Understand other student learning styles and interpretations

- Respond to email quickly

- Look at email daily

- Resourceful - use telephone when response is not delayed via email

The issue of professional working relationship between teams was noted as a major topic. This was seen to reinforce the realism of the assessment task, as well as to acknowledge the use of teams in industry.

The following quote (group 11, team 2) shows the importance of well-defined team tasks and compatible team members:

This term I have been involved in two groups over two different courses. I believe that the teamwork within Human Computer Interaction was more successful due to two reasons. Firstly the assignment criteria were very well specified (unlike the other course). This makes target setting within the group much 
Egea \& Gregor

easier. Within a distance education group it can be hard to have meaningful discussions, so having a clear work path makes the execution of an assignment much easier.

The second point (which I have already raised) is that I have been lucky enough to have a good group of people with a desire to achieve high marks (unlike my other group!). This is really a crucial factor. As a team member you are really at the mercy of the group. If you have a team member that is content to 'just pass' or allow other team members to perform the work it is really hard to motivate them into further participation. Just using electronic communication as a means to communicate with unwilling team members can be difficult. It is very easy to ignore emails.

\section{Issues in virtual team work}

Immediate feedback from team members was desired for student satisfaction in virtual teams. Students indicated that they used a number of communication channels to achieve this goal: for example, synchronous internet conferencing tools, telephone, email.

Students indicated that some penalty is needed for students who do not actively participate in the team presentations or reviews: different weightings to assignment marks, new team role, and to suggest a team leader to manage and organise the team. A more fatalistic approach was to accept that one's grade may not be as high as when one works one their own.

Other factors that caused student frustration included version control of presentation slides as one sends it to other team members for comment across email; and time zone changes particularly for international teams. Students noted that doing more than one course with team work was exhaustive and time consuming.

\section{Communication strategies}

The section describes the modes that students choose to communicate, including the different interaction styles, the modes of interpersonal communication, professional approaches in working a as team and the process of decision making and the need for team leaders.

\section{Range of virtual team communication}

All teams used email, and some used chat programs. The asynchronous method of communication was preferred for its simplicity of use, but students were most satisfied when other team members were online at the same time for 'near-synchronous' communication.

Interestingly, all teams which were based locally, regionally or intrastate, communicated with telephone as well as email. This was used when immediate feedback was necessary, as in the planning stages and the presentation week. The rationale given was that the telephone was instantaneous, provided immediate feedback while email depended on a response that may or may not occur over the next few days.

Communication styles were 'business like' whether using email, phone and face to face. The students mentioned that a professional level of interaction was sought. Phone was judged as the easier means to respond, followed by face-to-face meetings. Not all students sought face-to-face meetings indicating it was more convenient to use other modes of interaction. Additionally, interaction style depended on the assignment task and locality. For example, if a team has the same locality, interactions for the seminar presentation would more commonly be face-to-face meetings were predominate; with reviews being shared by email. 
Little communication occurred between an active team and the lecturer. However, when teams were reduced to a single member, more contact was requested by the student. This was done by email, in general.

\section{Interpersonal communication skills}

Virtual teams communicated predominately by email if interstate, intrastate or internationally-based team members were included in the team. For local teams, the email interaction was reduced to the medium to transport the attached files that needed team discussion. In most cases the teams meet physically at least for the initial meeting. Telephone was the second most used communication tool.

All teams were noted to interact in social interplay: discussing the course, stages in study program, family circumstances, and work. Once they discovered that they were in the same region, telephone numbers tended to be exchanged, as well as addresses. Students indicated that teams were useful to clarify their own thoughts by presenting them to others; and enabled students to be more articulate in their explanations.

From a summary of the data presented in the student responses to assessment questions given earlier, the following interpersonal communication skills were noted:

1. Style with email
a. More direct
b. Direct opinions,
c. Open and free discussion
d. Pose questions but give a suggested response

2. Tone of interaction:

a. Understanding and supportive tone

b. Positive tone

c. Good working environment:

d. Encouraging

e. complimentary

f. Tolerant of different communication methods

3. Communication style:

a. 'human-like' interaction: telephone is easier to achieve this

b. free and open

c. positive feedback

d. direct questions with possible solutions

e. Need to be efficient in presenting information/content

f. Need confidence to state a particular view even if at odds with other team members..(this is why the environment needs to be supportive )

g. Felt confident of other team members support and constructive critique and non personal critique

4. Collaborative discussion: 
a. Constructive criticism: Enabled an environment for conflict and discussion to improve seminar

b. Listen objectively to other view points

c. Understand other students circumstances

d. Negotiation

e. Compromise

f. Leant to communicate on a different level

\section{Professional attitudes}

Students indicated that it was important to set their own guidelines/rules for team operation, to include division of tasks for the seminar and time management timelines. The assignment was seen, in general, to portray authentic work situations. As such, students chose to work collaboratively and constructively. Few students engaged in personal criticism. Since the teams had three members, then such negative behaviour would be checked by other team members.

\section{Decision making and leadership}

In general, successful teams were quite explicit about the lack of team leader. They preferred to follow a collaborative model where all team members considered and debated issues sent to the mail list. Decisionmaking was therefore the responsibility of the team and not one individual. However, in teams, where not all members were motivated or enthusiastic, leadership structures arose. It appeared that these teams following directions of the leaders, and were without conflict with subordinate members. Leaders however, felt overworked. It was not the intention of the assignment to have inequality between members.

\section{Discussion and Conclusion}

This paper reports on student and lecturer experiences with virtual team work in a course on humancomputer interaction. The case study shows how the virtual teams worked, collaboration on a common task, critiques of team outputs, and reflections on the process overall supported the disciplinary material covered in Human-Computer Interaction. Reflections on the processes involved in successful teamwork indicated that important factors included clear goals for the team, good task organization, similar personal achievement goals among team member, reliability and efficiency, open communication styles, and respect and understanding for others in the team. These observations are congruent with other work reported in the literature.

Team members were able to show flexibility in their use of media, using phone for speed and when more complex discussion was necessary (for planning presentations) and email for "simpler" tasks, such as gaining agreement on critiques. Some teams supplemented these communication modes with chat groups and face-to-face meetings. Overall, student perceptions of the virtual-team approach were positive, recognizing the learning that contributed to understanding of course aims, as well as experiencing a work environment that is of increasing importance to organizations, as demonstrate by this student comment:

This subject has introduced a different style of learning. It seems the content is much less than that of other subjects, but I feel this is the type of interaction that will be prominent in business when students leave university. I have always disliked the style of learning adopted by many university lecturers. I feel students are educated in a wide variety of fields and specialising in none. Most subjects are called "Introduction to Analogue Electronics' and are nothing more than an introduction. I feel this subject provides a very real application of the students time, encouraging students to think as if they are in a business environment, to act in a professional manner, and conduct their studies/research/jobs like IT professionals. 
Reflections on Communication Processes and Virtual Teams

I think many other subjects could incorporate this style of interaction in the education of students (student, Group 14, team 5)

\section{References}

Aspin, M. (1999). Virtual Teams in Education: new management theories. Online Conference Paper presented at Net*Working 1999 Conference, Melbourne, September 1-3. Available at http://www.nw99.net.au/papers/aspin.html. [2001,10th December].

de Lisser, E. (1999, October 5, 1999). Update on Small Business: Firms with Virtual Environments Appeal to Workers. Wall Street Journal, pp. B2.

Deems, T. (1998). Vital Work: Adult Development Within the Natural Workplace. Paper presented at the 1998 Adult Education Research Conference.

Faucheux, C. (September 1997). How virtual organizing is transforming Management Science. Communications of the ACM, 40(9). Available at tttp://www.acm.org/cacm/, [2001,10th December].

Fisher, G., Bibo, M. \& Youngsmart,D.(2000). Virtual Teams and Enterpreneurship: Research Agenda. Paper presented Technological Entrepreneurship in the Emerging Regions of the New Millennium, Singapore, June 28-30, 2001.

Gay,G.,Sturgill,A.,Martin, W.\&Hutenlocher,D. (1999*. Document-centred Peer Collaborations: An Exploration of the Educational Uses of Networked Communication Technologies. Journal of Computer-Mediated Communication, 4(3). Available: http://www.ascusc.org/jcmc/vol4/issue3/gay.html [2001,11thDecember].

Hardwick, M. \& Bolton, R. (1997). The industrial virtual enterprise. Communications of the ACM, 40(9). Available at http://www.acm.org/cacm/, [2001,10th December].

Haythornthwaite, C.,Kazmer, M.M.,Robins, J.\& Shoemaker, S. (2000). Community development among distance Learners: Temporal and technological Dimensions. Journal of Computer-Mediated Communication, 6(1). Available: http://www.ascusc.org/jcmc/vol6/issue1/haythornthwaite.html [2001,12thDecember].

Jarvenpaa, S.L., Knoll,K. \& Leidner, D.E. (1998). Is anybody out there? Antecedents of trust in virtual teams. Journal Of Management Information Systems, 14 (4),29-65.

Jarvenpaa, S.L. \& Leidner, D.E. (1998). Communication and trust in globale virtual teams. Journal of Computer Mediated Communication, 3(4). Available: http://www.ascusc.org/jcmc/vol4/issue3/gay.html [2001,11thDecember].

Preece, J., Rogers, Y., Sharp, H., Benyon,D., Holland, S. \& Carey. T.(1994). Human Computer Interaction. The Open University, Addison-Wesley Longeman Limited, Essex, England.

Roberts,T.S., Romm,C.T.,\& Jones,D.(2000, December 8-10).Online Courses and Collaborative Learning: Underlying Philos,phies and Practices. Paper presented at IATM 2000 Conference, Brisbane.

Robey, D., Koo, H. M., \& Powers, C. (2000). Situated learning in cross-functional virtual teams. Technical Communication, 47(1), 51-66.

Romm, C. T. and Taylor, W. (2000) Thinking Creatively about On-line Education. In M.Khosrowpour(Ed.) Challenges of Information Technology Management in the 21st Century, (pp 1167-1169). Hershey. PA :Idea Group Publishing.

Smith, R. (2000). Learning in Virtual Teams: A summary of current literature. The issues/Problem. Available at http://www.msu.edu/\%7Esmithre9/Project12.htm. [2001, 12th December].

Turkle, S. (1995). Life On the Screen: Identity in the Age of the Internet. New York: Simon \& Schuster.

\section{Biography}

Kathy Egea is a Senior Lecturer in the Faculty of Informatics and Communications, in the School of Computing and Information Systems. Her teaching areas are undergraduate programming and Human Computer Interaction. She is eligible to graduate Doctor of Philosophy in June 2002 having achieved a clear pass in the thesis. The study focussed on education and technology in a bridging mathematics (developmental education program) distance study environment.

Ms Egea's current research interests include education and technology; computer-based placement and diagnostic testing in mathematics programs; test design in particular factors that minimise anxiety and 
promotes self-reflection; virtual teams; self-reflection in virtual study emvironments and tertiary pedagogy.

Shirley Gregor is Professor of Information Systems at the Australian National University, Canberra, where she heads the Electronic Commerce Research Group.

Professor Gregor's current research interests include electronic commerce and the theory of interorganizational systems, intelligent systems, and information systems development. She has led several large projects in the e-commerce area funded by the Meat Research Corporation, the Department of Communications, Information Technology and the Arts, and the Australian Research Council. Professor Gregor spent a number of years in the computing industry in Australia and the United Kingdom before beginning an academic career. She obtained her Ph.D. in Information Systems from the University of Queensland. Dr Gregor's publications include 2 edited books, 6 book chapters and over 60 papers in conferences and journals such as Management Information Systems Quarterly, International Journal of Human Computer Studies, European Journal of Information Systems and Information Technology \& People. 